\title{
Micellar Liquid Chromatography Determination of Spermine in Fish Sauce after Derivatization with 3,5-Dinitrobenzoyl Chloride
}

\author{
Mei-Liang Chin-Chen, ${ }^{1}$ Maria Rambla-Alegre, ${ }^{2}$ Samuel Carda-Broch, ${ }^{1}$ \\ Josep Esteve-Romero, ${ }^{1}$ and Juan Peris-Vicente ${ }^{1}$ \\ ${ }^{1}$ QFA, ESTCE, Universitat Jaume I, 12071 Castelló, Spain \\ ${ }^{2}$ Department of Organic Chemistry, Ghent University, 9000 Ghent, Belgium
}

Correspondence should be addressed to Juan Peris-Vicente, juan.peris@qfa.uji.es

Received 29 November 2011; Revised 14 January 2012; Accepted 17 January 2012

Academic Editor: Maria Jose Ruiz-Angel

Copyright (C) 2012 Mei-Liang Chin-Chen et al. This is an open access article distributed under the Creative Commons Attribution License, which permits unrestricted use, distribution, and reproduction in any medium, provided the original work is properly cited.

\begin{abstract}
A practical liquid chromatographic method has been developed for the selective determination of the levels of spermine in anchovy sauce after derivatization with 3,5 dinitrobenzoyl chloride. The micellar liquid chromatographic separation proposed here uses a C18 column $(125 \times 4.6 \mathrm{~mm})$, followed by detection of spermine derivative at $260 \mathrm{~nm}$. Elution of the analyte was performed using a mobile phase of $0.15 \mathrm{M}$ SDS- $4 \%(\mathrm{v} / \mathrm{v})$ 1-pentanol-pH 7 running under isocratic mode at $25^{\circ} \mathrm{C}$. Validation parameters were linearity $\left(2-100 \mu \mathrm{g} / \mathrm{mL}, R^{2}>0.999\right)$, detection and quantification limits $(0.4$ and $1.2 \mu \mathrm{g} / \mathrm{mL}$, resp.), precision (less than $3.6 \%$ ), accuracy (93.3-101.1\%), and robustness (less than 4.8\%). These results are in agreement with the requirements of the FDA guidelines. The proposed method was successfully applied to the monitorization of spermine formation in unsalted and salted fish sauce samples. The suggested methodology was found useful in routine analysis of spermine in fish sauce samples.
\end{abstract}

\section{Introduction}

Biogenic amines are biological metabolites present in foods either as natural products or after fermentation, decay microbial contamination, decomposition, or putrefaction processes [1]. They are largely responsible for the foul odour of putrefying flesh, as well as contributing to the odour of such processes as bad breath and bacterial vaginosis. Biogenic amines are also involved in local immune responses, neurotransmission, and chemotaxis of white blood cells. The consumption of an excess of biogenic amines, known as histaminic intoxication, is mainly related to heart, gastrointestinal, and skin diseases, as well as headache [1-3]. Food containing considerable amounts of these amines include alcoholic beverages, beef, chocolate, cheeses, fish, pork, and poultry. Biogenic amines can also be found in semen and some microalgae, together with related molecules like spermine and spermidine. In fact, spermine is formed from spermidine and can be found in a wide variety of organisms and tissues, as it is an essential growth factor in some bacteria. Thus, its detection and quantification is useful to assess the degree of bacterial contamination, mainly caused by incorrect handling or stocking conditions (freezer at $-18^{\circ} \mathrm{C}$ ), in fish flesh, or derivates as fish sauce. Then the determination of spermine is of the utmost importance to assure that the fish sauce can be eaten without health risk $[4,5]$.

Several analytical methods have been developed for the determination of spermine. Among them, HPLC with UVvisible absorbance detection using 3,5-dinitrobenzoyl chloride (DNBZ-Cl) as a chromophore has provided excellent results for quantification of biogenic amines in complex food samples. Derivatization reaction is quantitative, quite fast (less than $5 \mathrm{~min}$ ), and reproducible. The high stability and sensitivity of the obtained derivative makes it an excellent choice for the analysis of spermine $[2,6]$.

In these methods, the analytes have to undergo a previous extraction step in a suitable organic solvent, evaporation to dryness and redissolution in order to purify and preconcentrate the derivatized amines [6]. However, it introduces the risk of contamination and losing of the sample, improving the possibility of error and even increasing the analysis time [7-9]. Moreover, chromatographic conditions result in either 
insufficient separation, prolonged analysis times (higher than 1 hour) $[6,10]$ or need mobile phase running under a gradient program. This requires a stabilization time between two injections, lengthening analysis time and making difficult the analysis of a wide amount of samples [11]. These problems can be avoided by the use of micellar liquid chromatography (MLC), which usually allows direct injection of samples (after filtration), without needing any extraction and purification step [12-16]. Moreover, micellar mobile phases are less toxic, nonflammable, biodegradable, and relatively inexpensive in comparison to aqueous-organic solvents. MLC has proved to be a useful technique in the determination of a wide range of compounds in low time using mobile phases under isocratic conditions, by optimizing separation parameters $[12,13]$ including food samples [14-16].

The aim of this work was to develop a fast, simple, and selective procedure for the determination of spermine by MLC using a C18 column and UV detection. This analyte was derivatized with DNBZ-Cl to increase sensitivity, and directly injected in the chromatographic system. The suggested methodology was validated in terms of linearity, sensitivity, limits of detection and quantification, accuracy, precision, and recovery, following the FDA guideline [17]. Finally, the method was applied to the study of the anchovy sauce degradation by means of the determination of spermine depending on the storage treatment.

\section{Experimental}

2.1. Apparatus and Instrumentation. The $\mathrm{pH}$ was measured with a Crison GLP 22 (Barcelona, Spain) equipped with a combined $\mathrm{Ag} / \mathrm{AgCl} / \mathrm{glass}$ electrode. The balance used was a Mettler-Toledo AX105 Delta-Range (Greifensee, Switzerland). The vortex shaker and ultrasonification unit were from Selecta (Barcelona). The chromatographic system was an Agilent Technologies Series 1100 (Palo Alto, CA, USA) equipped with a quaternary pump, a thermostated autosampler, and column compartment. The dead time was determined as the mean value of the first significant deviation from the baseline in the chromatograms of the analyte. The signals were acquired by a PC computer connected to the chromatograph through an HP Chemstation.

2.2. Chemicals and Reagents. Spermine and 3,5-dinitrobenzoyl chloride (98\% pure) were purchased from SigmaAldrich (St. Louis, MO, USA). Sodium dodecyl sulphate (SDS) (99\% pure) was from Merck (Darmstadt, Germany); acetonitrile, 1-propanol, 2-propanol, 1-butanol, and 1-pentanol were from Scharlab (Barcelona), sodium dihydrogen phosphate, $\mathrm{HCl}$, and $\mathrm{NaOH}$ were from Panreac (Barcelona). All solutions were prepared in ultrapure water (Millipore, S.A.S. Molsheim, France). Mobile phases and samples were filtered through nylon membranes (Millex-HN, Millipore, Bedford, MA, USA). Spermine was dissolved in $0.1 \mathrm{M} \mathrm{HCl}$ to provide final concentrations of $100 \mu \mathrm{g} / \mathrm{mL}$.

2.3. Derivatization of Biogenic Amines with 3,5-Dinitrobenzoyl Chloride. Derivatising reagent $5 \mathrm{mM}$ 3,5-dinitrobenzoyl chloride (DNBZ-Cl) was dissolved in acetonitrile. Aliquots $(400 \mu \mathrm{L})$ of spermine (SP) standards, $1 \mathrm{M} \mathrm{NaOH}(1200 \mu \mathrm{L})$, 2-propanol $(700 \mu \mathrm{L})$ and 3,5-DNBZ-Cl $(2100 \mu \mathrm{L})$ were mixed in a reaction tube. After $3 \mathrm{~min}$ of shaking at $25^{\circ} \mathrm{C}, 2 \mathrm{M} \mathrm{HCl}$ $(1000 \mu \mathrm{L})$ was added to stop the reaction. Finally, after $1 \mathrm{~min}$ of shaking, derivatized sample was injected into the chromatographic system. Under these conditions, the formed derivative was (DNBZ) ${ }_{4} \mathrm{SP}[6]$. The fish sauce medium does not affect the derivatization reaction, because the conditions were strongly changed by the addition of organic alcohol and sodium hydroxide. Some matrix compounds are precipitated in 2-propanol/ $\mathrm{NaOH}$ media, and others are solubilized in the SDS medium $[2,6]$.

2.4. Chromatographic Conditions. Derivatized spermine elution was performed in a reversed-phase C18 column ( $125 \times$ $4.6 \mathrm{~mm}, 5 \mu \mathrm{m}$ particle size) from Scharlab thermostated at $25^{\circ} \mathrm{C}$. Mobile phase was a $0.15 \mathrm{M}$ SDS- $4 \%$ (v/v) 1-pentanol$\mathrm{NaH}_{2} \mathrm{PO}_{4} 0.01 \mathrm{M}$ solution at $\mathrm{pH} 7$, running under isocratic mode. Flowrate, injection volume, and UV wavelength were $1 \mathrm{~mL} / \mathrm{min}, 20 \mu \mathrm{L}$ and $260 \mathrm{~nm}$, respectively. Samples were thermostated at $+15^{\circ} \mathrm{C}$ in the autosampler module of the HPLC system to avoid decomposition of the spermine derivative [7]. Under these conditions, the retention time was $11.5 \mathrm{~min}$. Chromatographic signals were acquired and processed with an Agilent ChemStation (Rev. B.01.03).

2.5. Sample Preparation. Fish sauce samples of anchovies (Eugraulidea spp.) were obtained from a supermarket. A part of the anchovies was mixed with common salt in a relation of $75 / 25 \mathrm{w} / \mathrm{w}$ (a well-known treatment to avoid food spoilage) and another portion was untreated. In both cases, samples were stored at $+4^{\circ} \mathrm{C}$. For the analyses of fish sauces, $1 \mathrm{~g}$ was mixed with $0.5 \mathrm{~mL}$ of ethanol that was topped up to $10 \mathrm{~mL}$ with $0.1 \mathrm{M}$ SDS. Samples were derivatized as detailed in Section 2.3 and then they were injected directly into the chromatographic system without any other treatment then filtration.

Also, spiked samples were prepared by adding the appropriate volume of spermine standard solution (dissolved in $0.1 \mathrm{M} \mathrm{HCl}$ ) to $1 \mathrm{~g}$ of sample and then the mixture was vigorously shaken to favour homogenization and stored for one day at $+4^{\circ} \mathrm{C}$ to favour the contact between the analyte and the sample, as well as solvent evaporation $[18,19]$. Then the spiked sample was mixed with $0.5 \mathrm{~mL}$ of ethanol and topped up to $10 \mathrm{~mL}$ with $0.1 \mathrm{M}$ SDS solution. An aliquot of the sample $(400 \mu \mathrm{L})$ was derivatized as explained in Section 2.3, filtered and directly injected into the chromatograph $[2,6]$.

\section{Results and Discussion}

3.1. Optimization Strategy and Mobile Phase Selection. Mobile phases were aqueous solutions of SDS buffered at $\mathrm{pH} 7$ with phosphate buffer and the stationary phase was a C18 column $[2,6]$. The four $\mathrm{pK}_{\mathrm{a}}$ values of spermine lie in the interval 8-11 [20], so its retention behavior will not vary in the whole $\mathrm{pH}$ range of the $\mathrm{C} 18$ column used (2.5-7.5). In addition, working at $\mathrm{pH} 7$ increases the life of the column. 
TABLE 1: Intra- and interday precision (RSD, \%) and accuracy (recovery, \%) for spermine (*added concentrations expressed in $\mu \mathrm{g} / \mathrm{mL}$ ).

\begin{tabular}{|c|c|c|c|c|c|}
\hline \multicolumn{3}{|c|}{ Intraday precision $^{\mathrm{a}}(\mathrm{RSD}, \%)$} & \multicolumn{3}{|c|}{ Intraday accuracy ${ }^{\mathrm{a}}(\%)$} \\
\hline$* 2$ & 10 & 20 & 2 & 10 & 20 \\
\hline 3.6 & 2.5 & 1.8 & 93.3 & 97.4 & 99.0 \\
\hline \multicolumn{3}{|c|}{ Interday precision $^{\mathrm{b}}$ (RSD, \%) } & \multicolumn{3}{|c|}{ Interday accuracy ${ }^{\mathrm{b}}(\%)$} \\
\hline 2.5 & 1.8 & 0.7 & 96.2 & 101.0 & 99.5 \\
\hline
\end{tabular}

${ }^{\mathrm{a}} n=9 ;{ }^{\mathrm{b}} n=5$.

On the other hand, it should be highlighted that spermine is a polar compound, but the derivative $(\mathrm{DNBZ})_{4} \mathrm{SP}$ is quite hydrophobic [6]. Initially, the chromatographic parameters for the spermine derivative were obtained using a pure micellar mobile phase of SDS. Several mobile phases containing $0.05,0.1$, and $0.15 \mathrm{M}$ SDS were tested. At these three SDS concentrations, the retention times were found too high. Instead of increasing SDS concentration, the use of an aqueous solution of $0.15 \mathrm{M}$ SDS with a small amount of organic solvent was envisaged to reduce the retention time. Different amounts of 1-propanol and 1-butanol were tested and the retention time was reduced, but it remains very high (more than $60 \mathrm{~min}$ ), and with an irregular peak shape. Thus, 1pentanol was tested, and finally a mobile phase of $0.15 \mathrm{M}$ SDS-4\% (v/v) 1-pentanol allowed the elution of spermine derivative in an adequate retention time (nearly $11.5 \mathrm{~min}$ ). The chromatographic parameters for spermine derivative in this mobile phase were $k$ (retention factor) $=9.75 ; N$ (efficiency) $=4050$ theoretical plates, and $B / A$ (asymmetry factor $)=1.0$. Their calculation was performed as in [21] .

The possible interference of other compounds in spermine analysis was also studied. A blank of each matrix was performed by analyzing aliquots of unsalted and salted anchovy sauce free of spermine. The front shows a considerable maximal band height and width and no other peak was observed, indicating that all the substances elute at the dead time (Figure 1(a)). In fact, hydrophobic substances present in the matrices are introduced in micelles, thus avoiding their precipitation and allowing their fast elution. Moreover, the addition of 1-pentanol in the mobile phase improves its elution strength, reducing even more the retention time of matrix compounds. Samples of unsalted and salted anchovy sauce were spiked with $10 \mu \mathrm{g} / \mathrm{mL}$ of spermine. As can be seen in Figure 1(b), the chromatographic peak of spermine elutes far from the dead time and without overlapping with any other substances of the unsalted anchovy sauce matrix. The same result was found for the salted anchovy sauce samples. The selectivity of the analytical method has been assessed; it has been optimized by the separation of spermine from other interferences of the matrix. Other biogenic amines do not interfere in the determination of the spermine since they elute earlier $[2,7]$.

3.2. Method Validation. The whole validation was performed by spiking samples with spermine, following the Food and Drug Administration (FDA) guideline [17]. Unsalted and salted anchovy sauce samples were studied. Since results were found similar in both cases, only the obtained values for unsalted fish sauce are presented and discussed.
Calibration curves were constructed using the areas of the chromatographic peaks (nine replicates) obtained at seven different concentrations of spermine, in the 2$100 \mu \mathrm{g} / \mathrm{mL}$ range. To study the variability of the calibration parameters, the curves were obtained during 5 days over a period of two months for a different set of standards, and then the average value was considered. Results were similar in the two matrices studied. The slope and intercept were determined by the method of least square linear regression analysis, taking the absorbance in arbitrary units and the concentration in $\mu \mathrm{g} / \mathrm{mL}$. Limits of detection (LOD, 3s criterion) and quantification (LOQ, 10s criterion) for derivatized spermine using the proposed method $(n=10)$ were determined. The obtained parameters were slope, $0.15 \pm 0.01$; intercept, $0.02 \pm$ 0.03 ; determination coefficient $\left(R^{2}\right), 0.999$; LOD, $0.4 \mu \mathrm{g} / \mathrm{mL}$; and LOQ, $1.2 \mu \mathrm{g} / \mathrm{mL}$.

The intra- and interday precision and accuracy of spermine were determined by analysis of spiked samples at 2, 10 , and $20 \mu \mathrm{g} / \mathrm{mL}$. The intraday values were determined by assaying test solutions nine times on the same day, and interday value was the average of nine measurements of intra-day values taken on 5 days over a 3 -month period. The precision was taken as the RSD (\%) of the obtained areas, whereas the accuracy was the ratio between the calculated value of the recovered spermine and the spiked one $(\%)$. The results obtained were between $0.7-3.6 \%$ for precision and $93.3-101 \%$ for accuracy (Table 1). Both were in agreement with FDA guideline, which indicates that precision should be less than $15 \%$ and accuracy between 80 and 120\% [17].

Robustness of the method was examined by replicate injections $(n=6)$ of spermine spiked sample of unsalted anchovy sample at $10 \mu \mathrm{g} / \mathrm{mL}$ under small changes in the chromatographic parameters (SDS concentration, percentage of 1-pentanol, $\mathrm{pH}$ and flow rate). Insignificant differences in peak areas $(<4.8 \%)$ and less variability in retention time $(<3.5 \%)$ were observed (Table 2$)$. These results indicate that the selected factors remain unaffected by small variations in these parameters.

Stability studies indicated that the degradation of biogenic amines derivatizated with DNBZ-Cl took place in $12 \mathrm{~h}$ when kept in the fridge and in three hours at room temperature. These results were confirmed by the displacement of the peaks in chromatograms. The biogenic amine samples and the derivatizing reagent $\mathrm{DNBZ}-\mathrm{Cl}$ were stable for three days in the fridge and four months when kept in a freezer.

3.3. Analysis of Food Samples. Unsalted and salted anchovy sauces (Engraulidae spp.) were analyzed in different days in 


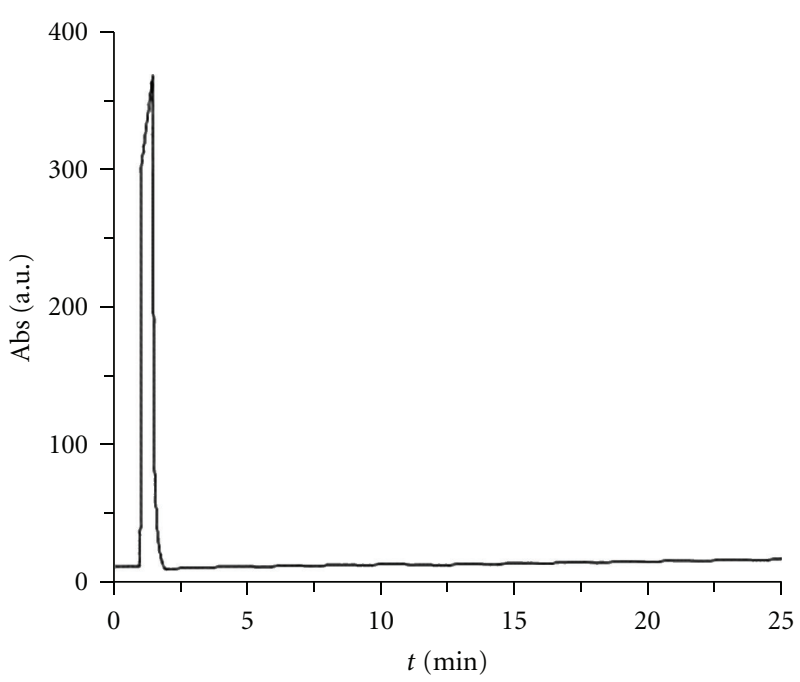

(a)

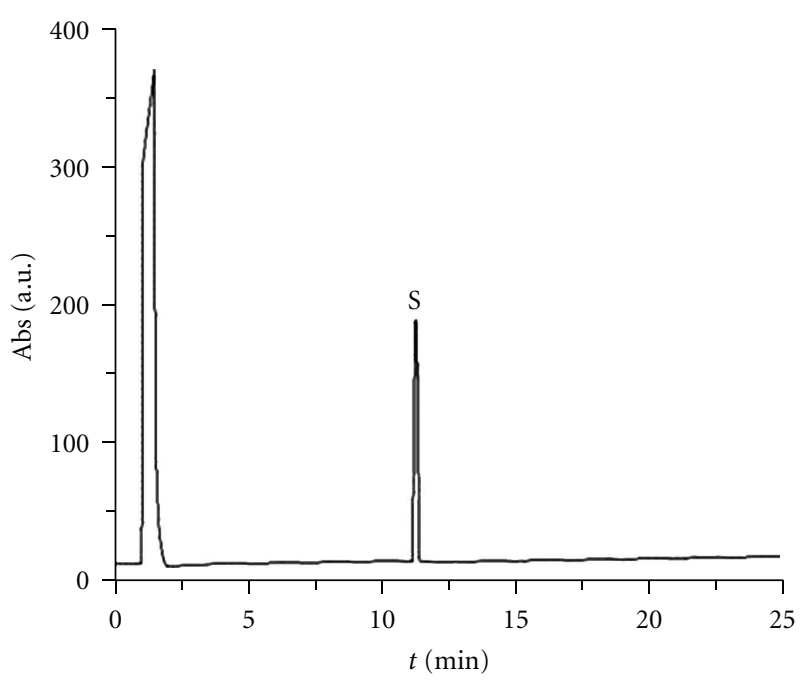

(b)

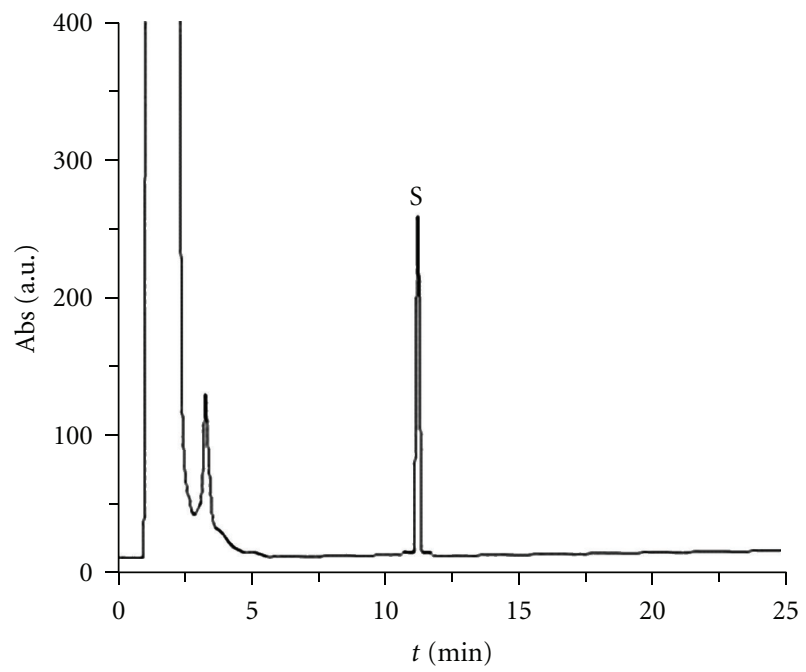

(c)

FIGURE 1: Chromatograms obtained by the analysis of unsalted anchovy sauce samples following the proposed methodology: (a) blank, (b) spiked with $10 \mu \mathrm{g} / \mathrm{mL}$ spermine, and (c) a real sample containing $15 \mu \mathrm{g} / \mathrm{mL}$ of spermine after 5-days storage. Chromatographic conditions: 0.15 M SDS-4\% (v/v) 1-pentanol-pH 7.

TABLE 2: Evaluation of the MLC method robustness.

\begin{tabular}{lccr}
\hline Changes in the parameters & Level & Retention time (min) (RSD, \%) & Area (RSD, \%) \\
\hline SDS $(\mathrm{M})$ & $0.145-0.155$ & $11.6 \pm 0.3(2.6)$ & $1.72 \pm 0.05(2.9)$ \\
1-Pentanol (\%) & $3.9-4.1$ & $11.8 \pm 0.4(3.4)$ & $1.68 \pm 0.08(4.8)$ \\
pH & $6.9-7.1$ & $11.5 \pm 0.2(1.7)$ & $1.66 \pm 0.04(2.4)$ \\
Flow (mL/min) & $0.95-1.05$ & $11.3 \pm 0.4(3.5)$ & $1.70 \pm 0.05(2.0)$ \\
\hline
\end{tabular}

$n=6$.

order to evaluate the microbacterial contamination depending on the storage conditions, by means of the amount or spermine. Figure 1(c) shows the chromatogram obtained by analysis of a real sample of unsalted anchovy sauce after 5 days of storage, where $15 \mu \mathrm{g} / \mathrm{mL}$ were detected without interferences. The amount of spermine after 1 month of storage was evaluated. Unsalted sample contained more than
$100 \mu \mathrm{g} / \mathrm{mL}$ of spermine, indicating a high microbacterial contamination (Figure 2). The unsalted anchovy sauce is spoilt and is unable to eat. However, the salted sample shows no microbacterial contamination (spermine level under LOD) and can be eaten without risk. These results indicate that salting is an efficient method to prevent microbial contamination during anchovy sauce storage. 


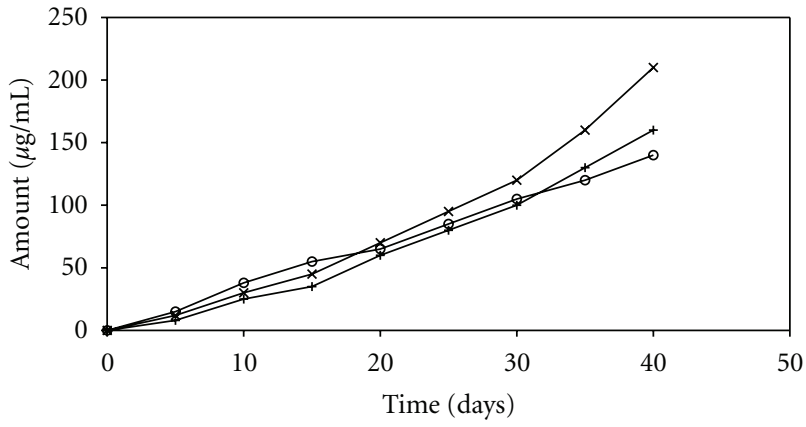

FIGURE 2: Amount found of spermine in three samples of unsalted anchovy sauce stored at $+4^{\circ} \mathrm{C}$ and analyzed by the proposed methodology in different days.

\section{Conclusions}

In conclusion, the results indicate that the micellar liquid chromatography procedure here developed can be used for the analysis of spermine, with analysis times below $12 \mathrm{~min}$. The analytical method is sensitive enough to be applied for quality control and routine analyses. It is a simple, rapid, effective, and alternative method and does not require any extraction step: the sample is directly injected after the derivatization procedure. The reagent 3,5-dinitrobenzoyl chloride was found to be highly suitable for the analysis of spermine with a very simple method and fast reaction at room temperature and is therefore recommended for use in pollution surveys, to study the degree of microbial contamination, and in the routine practice of food-quality control.

\section{Acknowledgments}

This work was supported by Fundació Caixa Castelló-Bancaixa P1-1B2006-12 projects and MEC CTQ 200764473/ BQU. M.-L. Chin-Chen also thanks the Foundation for its grant.

\section{References}

[1] M. Izquierdo-Pulido, T. Hernández-Jover, A. Mariné-Font, and M. C. Vidal-Carou, "Biogenic amines in European Beers," Journal of Agricultural and Food Chemistry, vol. 44, no. 10, pp. 3159-3163, 1996.

[2] M. Chin-Chen, D. Bose, J. Esteve-Romero, J. Peris-Vicente, M. Rambla-Alegre, and S. Carda-Broch, "Determination of putrescine and tyramine in fish by micellar liquid chromatography with UV detection using direct injection," The Open Analytical Chemistry Journal, vol. 5, pp. 22-26, 2011.

[3] S. Pons-Sánchez-Cascado, Study of alternatives to evaluate the freshness and quality of the anchovy, Doctoral thesis, University of Barcelona, 2004.

[4] S. Rodtong, S. Nawong, and J. Yongsawatdigul, "Histamine accumulation and histamine-forming bacteria in Indian anchovy (Stolephorus indicus)," Food Microbiology, vol. 22, no. 5, pp. 475-482, 2005.

[5] J. Yongsawatdigul, Y. J. Choi, and S. Udomporn, "Biogenic amines formation in fish sauce prepared from fresh and temperature-abused Indian anchovy (Stolephorus indicus)," Journal of Food Science, vol. 69, no. 4, pp. 312-319, 2004.

[6] J. Kirschbaum, K. Rebscher, and H. Brückner, "Liquid chromatographic determination of biogenic amines in fermented foods after derivatization with 3,5-dinitrobenzoyl chloride," Journal of Chromatography A, vol. 881, no. 1-2, pp. 517-530, 2000.

[7] J. Peris Vicente, J. V. Gimeno Adelantado, M. T. Doménech Carbó, R. Mateo Castro, and F. Bosch Reig, "Identification of lipid binders in old oil paintings by separation of 4-bromomethyl-7-methoxycoumarin derivatives of fatty acids by liquid chromatography with fluorescence detection," Journal of Chromatography A, vol. 1076, no. 1-2, pp. 44-50, 2005.

[8] J. Peris-Vicente, E. Simó-Alfonso, J. V. Gimeno Adelantado, and M. T. Doménech Carbó, "Direct infusion mass spectrometry as a fingerprint of protein-binding media used in works of art," Rapid Communications in Mass Spectrometry, vol. 19, no. 23, pp. 3463-3467, 2005.

[9] J. Peris-Vicente, R. Garrido-Medina, E. Simó-Alfonso, J. V. Gimeno-Adelantado, and M. T. Doménech-Carbó, "Infusion mass spectrometry as a fingerprint to characterize varnishes in oil pictorial artworks," Rapid Communications in Mass Spectrometry, vol. 21, no. 6, pp. 851-856, 2007.

[10] E. K. Paleologos, S. D. Chytiri, I. N. Savvaidis, and M. G. Kontominas, "Determination of biogenic amines as their benzoyl derivatives after cloud point extraction with micellar liquid chromatographic separation," Journal of Chromatography A, vol. 1010, no. 2, pp. 217-224, 2003.

[11] J. Peris-Vicente, J. V. Gimeno Adelantado, M. T. D. Carbó, R. M. Castro, and F. B. Reig, "Characterization of proteinaceous glues in old paintings by separation of the o-phtalaldehyde derivatives of their amino acids by liquid chromatography with fluorescence detection," Talanta, vol. 68 , no. 5, pp. 16481654, 2006.

[12] J. Esteve-Romero, E. Ochoa-Aranda, D. Bose, M. RamblaAlegre, J. Peris-Vicente, and A. Martinavarro-Domínguez, "Tamoxifen monitoring studies in breast cancer patients by micellar liquid chromatography," Analytical and Bioanalytical Chemistry, vol. 397, no. 4, pp. 1557-1561, 2010.

[13] E. O. Aranda, J. Esteve-Romero, M. Rambla-Alegre, J. PerisVicente, and D. Bose, "Development of a methodology to quantify tamoxifen and endoxifen in breast cancer patients by micellar liquid chromatography and validation according to the ICH guidelines," Talanta, vol. 84, no. 2, pp. 314-318, 2011.

[14] M. Rambla-Alegre, J. Peris-Vicente, J. Esteve-Romero, and S. Carda-Broch, "Analysis of selected veterinary antibiotics in fish by micellar liquid chromatography with fluorescence detection and validation in accordance with regulation 2002/ 657/EC," Food Chemistry, vol. 123, no. 4, pp. 1294-1302, 2010.

[15] S. Marco-Peiró, B. Beltrán-Martinavarro, M. Rambla-Alegre, J. Peris-Vicente, and J. Esteve-Romero, "Validation of an analytical methodology to quantify melamine in body fluids using micellar liquid chromatography," Talanta, vol. 88, pp. 617$622,2012$.

[16] B. Beltrán-Martinavarro, J. Peris-Vicente, S. Marco-Peiró, J. Esteve-Romero, M. Rambla-Alegre, and S. Carda-Broch, "Use of micellar mobile phases for the chromatographic determination of melamine in dietetic supplements," Analyst, vol. 137, no. 1, pp. 269-274, 2012.

[17] FDA Guidance for Industry, Bioanalytical Method Validation, U.S. Department of Health and Human Services. Food and Drug Administration, Rockville, Md, USA, 2001. 
[18] G. Cano-Sancho, S. Marin, A. J. Ramos, J. Peris-Vicente, and V. Sanchis, "Occurrence of aflatoxin M1 and exposure assessment in Catalonia (Spain)," Revista Iberoamericana de Micologia, vol. 27, no. 3, pp. 130-135, 2010.

[19] J. Peris Vicente, J. V. Gimeno Adelantado, M. T. Doménech Carbó, R. Mateo Castro, and F. Bosch Reig, "Identification of drying oils used in pictorial works of art by liquid chromatography of the 2-nitrophenylhydrazides derivatives of fatty acids," Talanta, vol. 64, no. 2, pp. 326-333, 2004.

[20] C. Frassineti, S. Ghelli, P. Gans, A. Sabatini, M. S. Moruzzi, and A. Vacca, "Nuclear magnetic resonance as a tool for determining protonation constants of natural polyprotic bases in solution," Analytical Biochemistry, vol. 231, no. 2, pp. 374382, 1995.

[21] M. Rambla-Alegre, J. Peris-Vicente, S. Marco-Peiró, B. Beltrán-Martinavarro, and J. Esteve-Romero, "Development of an analytical methodology to quantify melamine in milk using micellar liquid chromatography and validation according to EU Regulation 2002/654/EC," Talanta, vol. 81, no. 3, pp. 894900, 2010. 


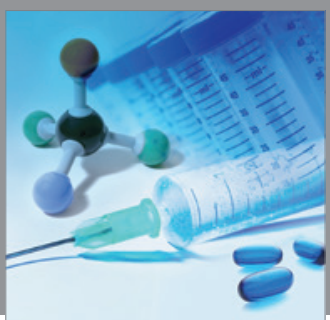

International Journal of

Medicinal Chemistry

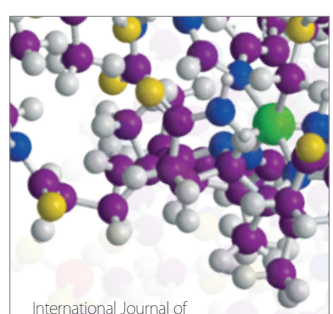

Carbohydrate Chemistry

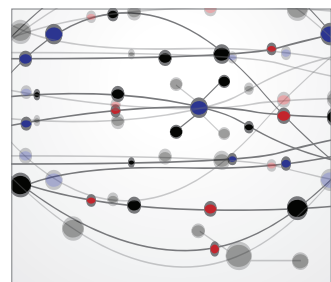

The Scientific World Journal
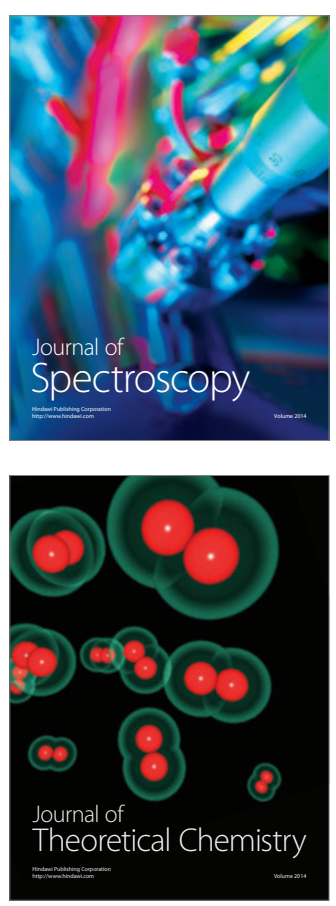
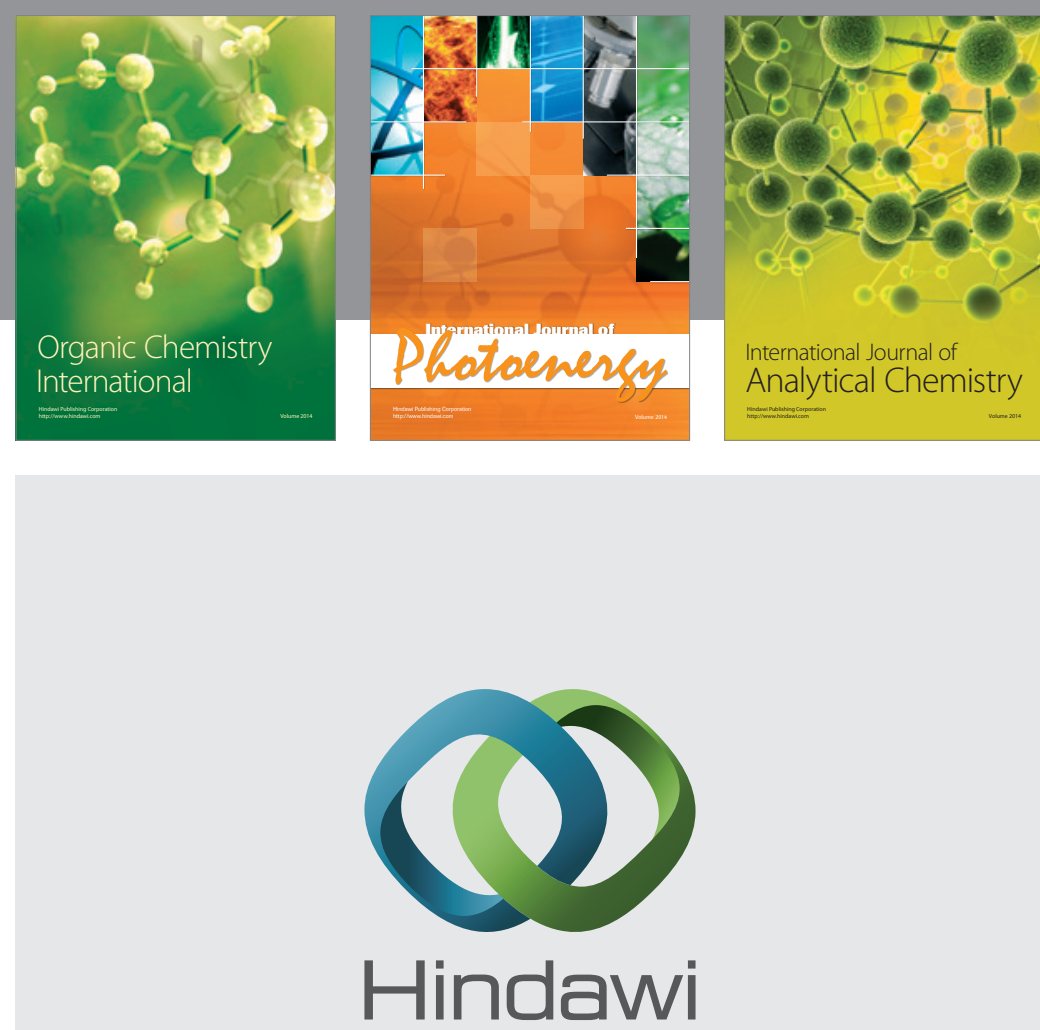

Submit your manuscripts at

http://www.hindawi.com
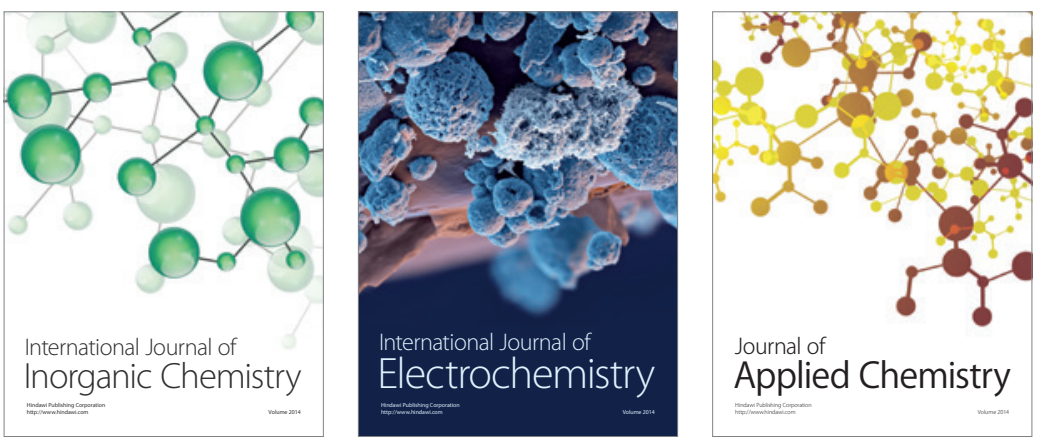

Journal of

Applied Chemistry
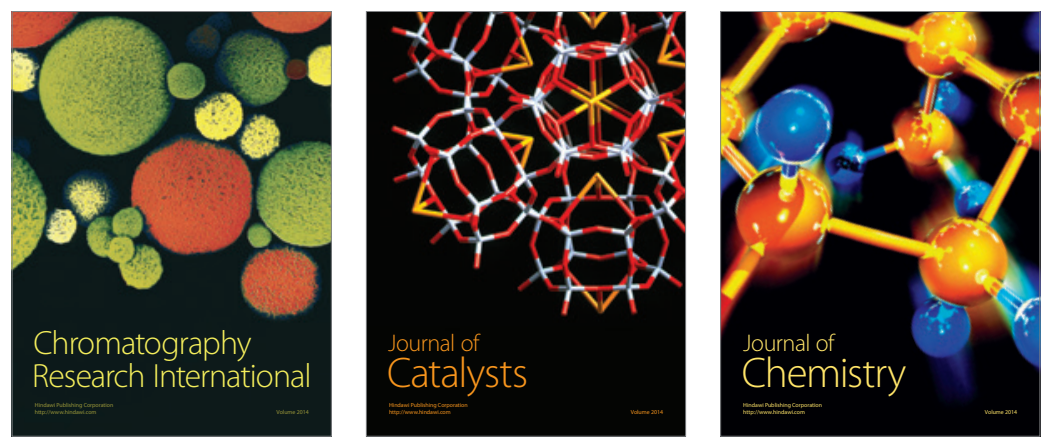
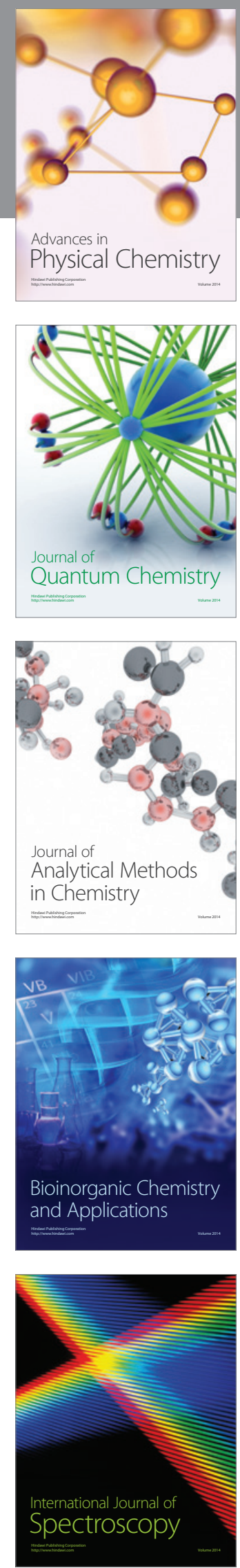